\title{
Equol promotes rat osteoblast proliferation and differentiation through activating estrogen receptor
}

\author{
J. Wang ${ }^{1,2,3}$, J. Xu ${ }^{4}$, B. Wang ${ }^{1,2}$, F.R. Shu ${ }^{1,2}$, K. Chen ${ }^{1,2}$ and M.T. Mi ${ }^{1,2}$ \\ ${ }^{1}$ Department of Nutrition and Food Hygiene, \\ College of Military Preventive Medicine, \\ Third Military Medical University, Chongqing, China \\ ${ }^{2}$ Chongqing Key Laboratory of Nutrition and Food Safety, \\ Chongqing Medical Nutrition Research Center, Chongqing, China \\ ${ }^{3}$ Department of Nutrition, Xinqiao Hospital, \\ Third Military Medical University, Chongqing, China \\ ${ }^{4}$ Department of Endocrinology, Xinqiao Hospital, \\ Third Military Medical University, Chongqing, China \\ Corresponding author: M.T. Mi \\ E-mail: mimantian@126.com
}

Genet. Mol. Res. 13 (3): 5055-5063 (2014)

Received July 1, 2013

Accepted December 3, 2013

Published July 4, 2014

DOI http://dx.doi.org/10.4238/2014.July.4.21

\begin{abstract}
Phytoestrogens have been suggested as alternative treatment for postmenopausal osteoporosis. Equol, a metabolite of daidzein, has been shown to inhibit bone loss in ovariectomized mice and rats. However, whether or not equol influences the formation of bone has not yet been investigated. Therefore, we investigated the effect of equol on the proliferation and differentiation of rat primary osteoblasts and explored the involved mechanisms. Different equol concentrations significantly promoted the proliferation of osteoblasts after 48- and 72-h incubations. The alkaline phosphatase (ALP) activity also increased significantly in all of the equol and $17 \beta$-estradiol $\left(\mathrm{E}_{2}\right)$ groups, except for the lowest $(0.01 \mu \mathrm{M})$ equol group. Equol also significantly elevated the
\end{abstract}


osteocalcin levels. The effects of equol on osteoblast proliferation, ALP activity, and osteocalcin levels were blocked by the estrogen receptor (ER) antagonist ICI182780. After a 24-h incubation, the expression of protein kinase $\mathrm{C}$ alpha $(\mathrm{PKC} \alpha)$ in osteoblasts was significantly increased by equol. In conclusion, our study demonstrated that equol could promote the proliferation and differentiation of rat osteoblasts through activating the ER-PKC $\alpha$-related signaling pathway, suggesting that equol could promote bone formation. These results suggest that equol could be a potential alternative agent for the management of postmenopausal osteoporosis.

Key words: Osteoblast; Osteoblast proliferation; Equol; Postmenopausal osteoporosis; Osteoblast differentiation

\section{INTRODUCTION}

Estrogen deficiency is recognized as the main reason for the occurrence of osteoporosis in postmenopausal women (Riggs et al., 2002). Due to the side effects of hormonal replacement therapy, phytoestrogens, which are plant-derived substances with estrogenic activity, have been suggested as alternatives for the treatment of postmenopausal osteoporosis without displaying cancer-related side effects (Zavatti et al., 2013).

Among the phytoestrogens, isoflavones have been shown to be capable of increasing the bone mineral density in ovariectomized animals and postmenopausal women (Occhiuto et al., 2007; Shedd-Wise et al., 2011; Chang et al., 2013). Equol, a metabolite of daidzein, which is a major isoflavone of soybean, is more biologically active than any other isoflavone aglycone (Yuan et al., 2007; Setchell and Clerici, 2010). Equol was shown to inhibit bone loss in ovariectomized mice and rats (Fujioka et al., 2004; Ohtomo et al., 2008; Kolios et al., 2009). In an in vitro study, equol significantly inhibited the osteoclast formation induced by $1 \alpha, 25(\mathrm{OH})_{2} \mathrm{D}_{3}$ (Ohtomo et al., 2008). However, whether or not equol might influence the formation of bone has not yet been investigated. Therefore, we aimed to study the effect of equol on the proliferation and differentiation of rat primary osteoblasts and to explore the involved mechanisms.

\section{MATERIAL AND METHODS}

\section{Reagents}

Alpha minimum essential medium ( $\alpha$-MEM) and fetal bovine serum (FBS) were purchased from Hyclone (Logan, UT, USA). Equol, 17ß-estradiol ( $\left.\mathrm{E}_{2}\right)$, ICI182780, vitamin C, and sodium $\beta$-glycerophosphate ( $\beta$-GP) were purchased from Sigma-Aldrich (St. Louis, MO, USA). P-nitrophenol phosphate and the alkaline phosphatase (ALP) and hydroxyproline assay kits were purchased from the Nanjing Jiancheng Biological Engineering Institute.

\section{Cell culture}

Primary osteoblasts were isolated from neonatal calvaria of 1-day-old Wistar rats as 
described previously (Hu et al., 2012). Briefly, calvaria of neonatal rats were cut into small pieces and cultured for 5 days on collagen gel prepared in $\alpha$-MEM containing $10 \%$ FBS. Preosteoblasts grown from the calvarium were collected by treatment of collagen gel cultures with collagenase, and were then further cultured in $\alpha$-MEM with $10 \%$ FBS. The medium was changed three times a week.

\section{3-[4,5-dimethylthiazol-2-yl]-2,5 diphenyl tetrazolium bromide (MTT) assay}

Primary rat osteoblasts were seeded on 96 -well plates at a $1 \times 10^{4}$ cells/well density in phenol-red-free $\alpha$-MEM supplemented with $10 \%$ charcoal-stripped FBS $24 \mathrm{~h}$ before treatment with $0.01-1 \mu \mathrm{M}$ equol, 0.01-1 $\mu \mathrm{M} \mathrm{E}_{2}$, or 0.01-1 $\mu \mathrm{M}$ equol/ $\mathrm{E}_{2}$ combined with $1 \mu \mathrm{M}$ ICI182780. Twenty-four or forty-eight hours later, $10 \mu \mathrm{L} 5 \mathrm{mg} / \mathrm{mL}$ MTT solution was added to each well. The plates were incubated at $37^{\circ} \mathrm{C}$ for $4 \mathrm{~h}$, and then the supernatant was discarded and $100 \mu \mathrm{L}$ dimethyl sulfoxide was added to each well and mixed thoroughly before taking measurements in a microplate reader.

\section{Measurement of ALP activity}

Primary rat osteoblasts were seeded onto 24 -well plates at a $1 \times 10^{5}$ cells/well density in phenol-red-free $\alpha$-MEM supplemented with $10 \%$ charcoal-stripped FBS. After $24 \mathrm{~h}$, they were subsequently cultured for 7 or 14 days in differentiation medium consisting of $50 \mathrm{mg} / \mathrm{L}$ ascorbic acid and $10 \mathrm{mM} \beta$-GP. The cultures on 24-well plates were rinsed with phosphatebuffered saline. The cells were sonicated in $0.1 \mathrm{M}$ Tris buffer, $\mathrm{pH} 7.2$, containing $0.1 \%$ Triton$\mathrm{X}-100$. The ALP activity was measured with an ALP detection kit according to manufacturer instructions.

\section{Statistical analysis}

Data are reported as means $\pm \mathrm{SD}$. Statistical analysis was performed using ANOVA followed by Fisher protected least significant differences. $\mathrm{P}<0.05$ was considered to be statistically significant.

\section{RESULTS}

\section{Identification of primary osteoblasts by ALP staining}

The morphology of the cultured osteoblast cells was observed under a light microscope (Figure 1A). There were many shapes of osteoblasts observed, including stellate-shaped, short spindle-shaped, and fusiform-shaped cells. Osteoblast staining showed that there were many ALP-positive dark brown or black particles in the cytoplasm of the cells (Figure 1B), suggesting that the isolated cells were indeed osteoblasts.

\section{Effect of equol on the proliferation of primary osteoblasts}

To investigate the effect of equol on the proliferation of cultured osteoblasts, the MTT 
assay was performed. The results showed that all of the equol concentrations tested promoted the proliferation of osteoblasts after 48- and 72-h incubations, which was consistent with the effect of $\mathrm{E}_{2}$ (Figure 2). This effect was blocked by the estrogen receptor (ER) antagonist ICI182780.
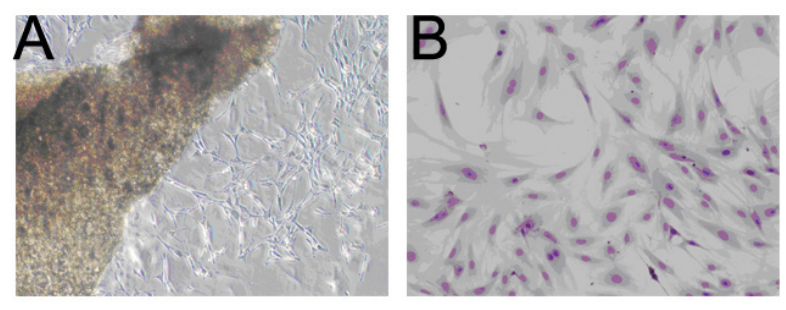

Figure 1. Identification of isolated rat osteoblasts. A. Light microscope observation of the osteoblasts (40X). B. ALP staining of the isolated osteoblasts (100X).

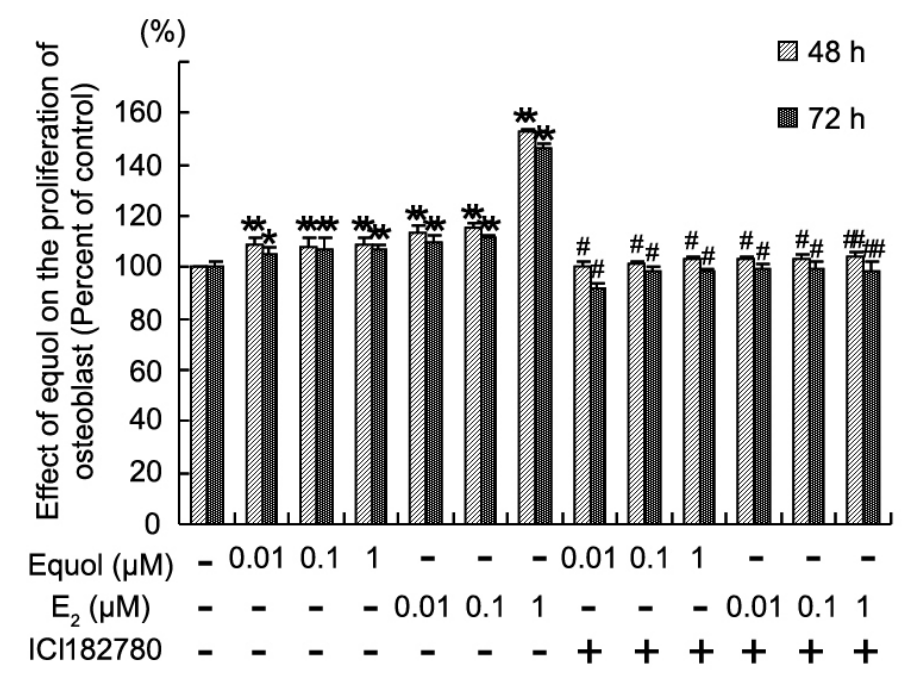

Figure 2. Effect of equol on the proliferation of primary osteoblasts. Osteoblasts were seeded on 96-well plates. After $24 \mathrm{~h}$, the cells were treated with equol $(0.01-1 \mu \mathrm{M}), \mathrm{E}_{2}(0.01-1 \mu \mathrm{M})$ or equol/ $\mathrm{E}_{2}(0.01-1 \mu \mathrm{M})$ combined with ICI1 $82780(1 \mu \mathrm{M})$ for 48 or $72 \mathrm{~h}$, then MTT assay was performed. $* \mathrm{P}<0.05,{ }^{*} \mathrm{P}<0.01$, compared with the control group; ${ }^{\mathrm{P}}<0.05,{ }^{\#} \mathrm{P}<0.01$ compared with equol or $\mathrm{E}_{2}$ groups at the same concentration.

\section{Effect of equol on the ALP activity of primary osteoblasts}

To further study the effect of equol on the differentiation of cultured osteoblasts, we determined the ALP activity of the osteoblasts. After 48- and 72-h incubations with different equol or $\mathrm{E}_{2}$ concentrations, the ALP activity increased significantly in all of the equol and $\mathrm{E}_{2}$ groups except for the $0.01 \mu \mathrm{M}$ equol group (Figure 3). When co-incubated with ICI182780, the effects of equol and $\mathrm{E}_{2}$ on the ALP activity were abolished. 


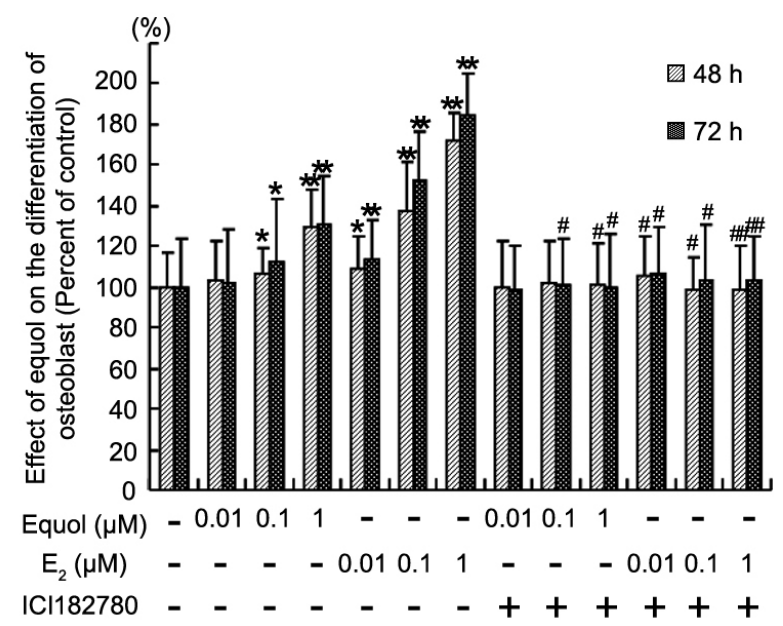

Figure 3. Effect of equol on the ALP activity of primary osteoblasts. Osteoblasts were seeded on 12-well plates. After $24 \mathrm{~h}$, the cells were treated with equol $(0.01-1 \mu \mathrm{M}), \mathrm{E}_{2}(0.01-1 \mu \mathrm{M})$ or equol/ $\mathrm{E}_{2}(0.01-1 \mu \mathrm{M})$ combined with ICI182780 $(1 \mu \mathrm{M})$ for 48 or $72 \mathrm{~h}$, then ALP activity was determined as described above. $* \mathrm{P}<0.05, * * \mathrm{P}<0.01$, compared with the control group; ${ }^{\#} \mathrm{P}<0.05,{ }^{\#} \mathrm{P}<0.01$ compared with equol or $\mathrm{E}_{2}$ groups at the same concentration.

\section{Effect of equol on the osteocalcin level in primary osteoblasts}

Next, the osteocalcin levels in osteoblasts were examined. The results showed that the osteocalcin levels in the equol- or $\mathrm{E}_{2}$-treated osteoblasts were increased significantly (Figure 4). Equol showed a weak effect on the regulation of osteocalcin levels at the same concentration. The effects of both equol and $\mathrm{E}_{2}$ on osteocalcin levels were blocked by ICI182780.

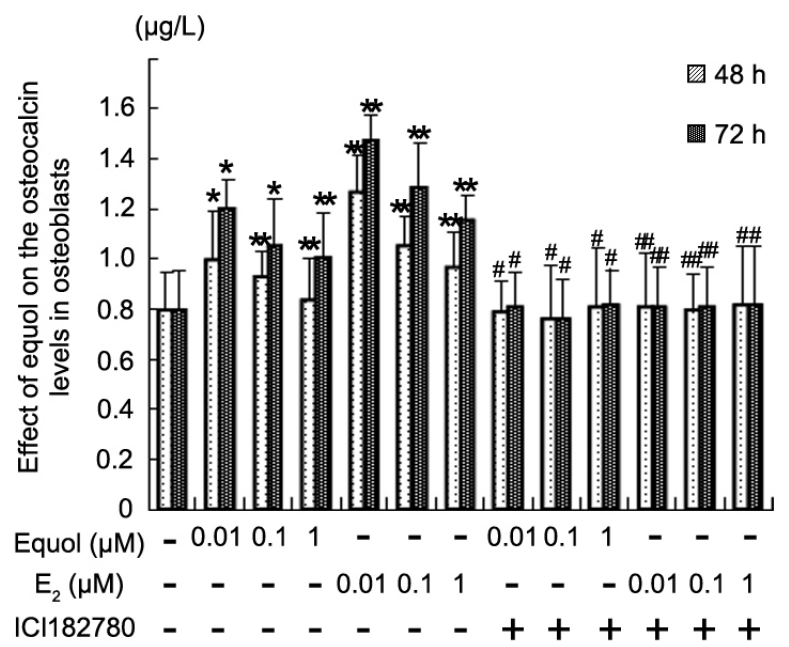

Figure 4. Effect of equol on the osteocalcin in primary osteoblasts. Osteoblasts were seeded on 12-well plates. After $24 \mathrm{~h}$, the cells were treated with equol $(0.01-1 \mu \mathrm{M}), \mathrm{E}_{2}(0.01-1 \mu \mathrm{M})$ or equol/ $\mathrm{E}_{2}(0.01-1 \mu \mathrm{M})$ combined with ICI182780 $(1 \mu \mathrm{M})$ for 48 or $72 \mathrm{~h}$, then the osteocalcin levels were determined. $* \mathrm{P}<0.05, * * \mathrm{P}<0.01$, compared with the control group; ${ }^{\#} \mathrm{P}<0.05,{ }^{\#} \mathrm{P}<0.01$ compared with equol or $\mathrm{E}_{2}$ groups at the same concentration. 


\section{Equol upregulated the expression of protein kinase $\mathrm{C}$ alpha (PKCa)}

Finally, we determined the expression of PKC $\alpha$ after a 24-h incubation with equol or $\mathrm{E}_{2}$. As shown in Figure 5, the expression of PKC $\alpha$ was significantly increased in both equoland $\mathrm{E}_{2}$-treated cells.

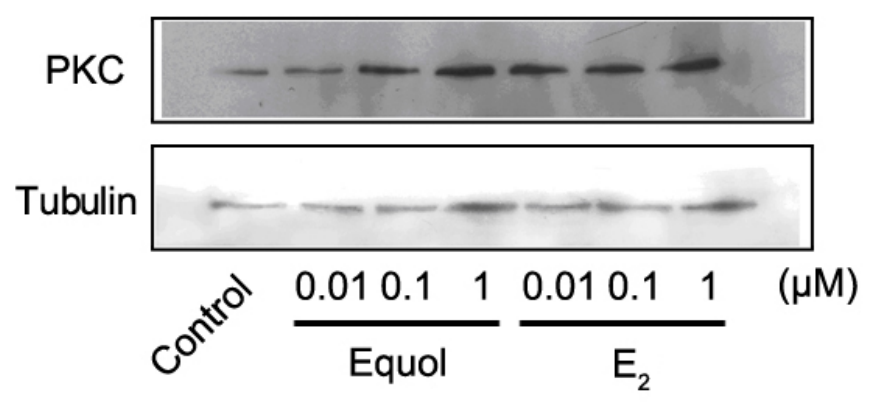

Figure 5. Effect of equol on the expression of PKCa. Osteoblasts were seeded on 6-well plates. After $24 \mathrm{~h}$, the cells were treated with or without equol $(0.01-1 \mu \mathrm{M})$ or $\mathrm{E}_{2}(0.01-1 \mu \mathrm{M})$ for another $24 \mathrm{~h}$. The levels of PKC $\alpha$ were examined by Western blot.

\section{DISCUSSION}

In the present study, our results showed that equol could promote the proliferation, and increase the ALP activity and osteocalcin levels of primary osteoblasts, and that these effects were blocked by the ER antagonist ICI182780. In addition, equol elevated the expression of PKC $\alpha$, suggesting that the effects of equol are mediated by a PKC-related pathway.

Bone is one of the most important target organs of estrogen. Estrogen deficiency has been recognized as one of the most important causes of osteoporosis, particularly in menopausal women (Corina et al., 2012; Tyagi et al., 2012). Hormone therapy is widely used for the management and prevention of postmenopausal osteoporosis in older women; however, the occurrence of undesired side effects has limited the use of hormone therapy (Bakhireva et al., 2010). Previous studies have shown that phytoestrogens are a suitable alternative for the treatment of postmenopausal osteoporosis (Al-Anazi et al., 2011; Zavatti et al., 2013). Phytoestrogens could exert weak estrogen-like effects without the side effects of estrogen (Dang and Lowik, 2005). Soy isoflavone, which is a type of phytoestrogen with a similar molecular structure to estrogen, could combine with the ER (Tang et al., 2008). In previous studies, soy isoflavones and their metabolites, soy isoflavone aglycones, were shown to be capable of reducing bone loss in ovariectomized rats, suggesting that soy isoflavone and its metabolites may be active substances in the prevention of osteoporosis in postmenopausal women (Mathey et al., 2007; Shiguemoto et al., 2007). However, the outcomes of soy isoflavone treatment for the prevention of menopausal bone loss are conflicting. Although many researchers have shown that daily supplementation with soy isoflavones could prevent postmenopausal osteoporosis and improve bone strength, thus decreasing the risk of fracture in menopausal women (Wong et al., 2009; Taku et al., 2010, 2011), other studies have indicated that the daily administration of soy isoflavones could not prevent bone loss in menopausal women (Arjmandi et al., 2005; Levis et al., 2011). 
Equol is a metabolic end-product of soy isoflavones with high stability and a slow excretion speed. In addition, it has stronger physiological activity compared to its precursor soy isoflavone aglycone. In the current study, we showed that equol could promote the proliferation of primary cultured osteoblasts. We also evaluated the effects of equol on osteoblast differentiation by measuring two osteoblast differentiation markers, ALP and osteocalcin. The results showed that equol enhanced ALP activity and increased the osteocalcin content. The stimulatory effect of equol on osteoblast proliferation, ALP activity, and osteocalcin content was blocked by the ER antagonist ICI182780, suggesting that equol acts as an ER agonist on osteoblasts. However, it was previously found that only 30 to $50 \%$ of individuals produce equol, and the metabolic ability of equol differs among different races (Setchell et al., 2003; Jou et al., 2008). Therefore, the controversial results of soy isoflavones in the management of postmenopausal osteoporosis may be due to differences in the production and metabolism of equol in different populations.

PKC signaling mediates various cellular functions, such as cell proliferation and differentiation, and the signaling of various osteogenic regulators, such as parathyroid hormone and estrogen (Migliaccio et al., 1998; Capiati et al., 1999; Lampasso et al., 2002; Longo et al., 2006). Inhibition of PKC $\alpha$ activity in osteoblasts results in a marked decrease in mitogenactivated protein kinase activity, which is known to play an important role in the proliferation of cells, leading to a significant decrease in proliferation (Lampasso et al., 2002); on the other hand, activation of PKC $\alpha$ promotes human osteoblast proliferation (Villa et al., 2003; Hsieh et al., 2010; Liang et al., 2012). In rat and human osteoblast-like cell lines, PKC signaling can induce the transcription of osteocalcin (Boguslawski et al., 2000). However, the function of $\mathrm{PKC} \alpha$ in osteoblast differentiation is controversial. $\mathrm{PKC} \alpha$ is necessary for basic fibroblast growth factor-induced bone formation (Tang et al., 2004), whereas in MC3T3-E1 cells, overexpression of PKC $\alpha$ decreases ALP activity and attenuates osteoblastic differentiation (Nakura et al., 2011). In this study, we showed that both equol and $\mathrm{E}_{2}$ upregulated the expression of PKCa, suggesting that the effect of equol on osteoblast proliferation, ALP activity, and osteocalcin content may be mediated by PKC $\alpha$-related signaling.

In conclusion, our study demonstrated that equol may promote the proliferation and differentiation of rat osteoblasts through activating the ER-PKC $\alpha$-related signaling pathway, suggesting that equol may promote bone formation. These results suggest that equol could be a potential alternative agent for the management of postmenopausal osteoporosis. However, since this is only an in vitro study, further studies should be performed to validate the antipostmenopausal osteoporosis effects of equol in vivo.

\section{ACKNOWLEDGMENTS}

Research supported by the National Natural Science Foundation of China (\#81273058) and the Special Funds of Chongqing Key Laboratory for Independent Research Projects (\#2011).

\section{Conflicts of interest}

The authors declare no conflict of interest.

\section{REFERENCES}

Al-Anazi AF, Qureshi VF, Javaid K and Qureshi S (2011). Preventive effects of phytoestrogens against postmenopausal osteoporosis as compared to the available therapeutic choices: An overview. J. Nat. Sci. Biol. Med. 2: 154-163. 
Arjmandi BH, Lucas EA, Khalil DA, Devareddy L, et al. (2005). One year soy protein supplementation has positive effects on bone formation markers but not bone density in postmenopausal women. Nutr. J. 4: 8 .

Bakhireva LN, Shainline MR, Carter S, Robinson S, et al. (2010). Synergistic effect of statins and postmenopausal hormone therapy in the prevention of skeletal fractures in elderly women. Pharmacotherapy 30: 879-887.

Boguslawski G, Hale LV, Yu XP, Miles RR, et al. (2000). Activation of osteocalcin transcription involves interaction of protein kinase A- and protein kinase C-dependent pathways. J. Biol. Chem. 275: 999-1006.

Capiati DA, Tellez-Inon MT and Boland RL (1999). Participation of protein kinase C alpha in 1,25-dihydroxy-vitamin D3 regulation of chick myoblast proliferation and differentiation. Mol. Cell Endocrinol. 153: 39-45.

Chang KL, Hu YC, Hsieh BS, Cheng HL, et al. (2013). Combined effect of soy isoflavones and vitamin D3 on bone loss in ovariectomized rats. Nutrition 29: 250-257.

Corina M, Vulpoi C and Branisteanu D (2012). Relationship between bone mineral density, weight, and estrogen levels in pre and postmenopausal women. Rev. Med. Chir. Soc. Med. Nat. Iasi 116: 946-950.

Dang ZC and Lowik C (2005). Dose-dependent effects of phytoestrogens on bone. Trends Endocrinol. Metab. 16: 207-213.

Fujioka M, Uehara M, Wu J, Adlercreutz H, et al. (2004). Equol, a metabolite of daidzein, inhibits bone loss in ovariectomized mice. J. Nutr. 134: 2623-2627.

Hsieh CP, Chiou YL and Lin CY (2010). Hyperbaric oxygen-stimulated proliferation and growth of osteoblasts may be mediated through the FGF-2/MEK/ERK 1/2/NF-kappaB and PKC/JNK pathways. Connect. Tissue Res. 51: 497-509.

Hu YC, Cheng HL, Hsieh BS, Huang LW, et al. (2012). Arsenic trioxide affects bone remodeling by effects on osteoblast differentiation and function. Bone 50: 1406-1415.

Jou HJ, Wu SC, Chang FW, Ling PY, et al. (2008). Effect of intestinal production of equol on menopausal symptoms in women treated with soy isoflavones. Int. J. Gynaecol. Obstet. 102: 44-49.

Kolios L, Sehmisch S, Daub F, Rack T, et al. (2009). Equol but not genistein improves early metaphyseal fracture healing in osteoporotic rats. Planta Med. 75: 459-465.

Lampasso JD, Marzec N, Margarone J III and Dziak R (2002). Role of protein kinase C alpha in primary human osteoblast proliferation. J. Bone Miner. Res. 17: 1968-1976.

Levis S, Strickman-Stein N, Ganjei-Azar P, Xu P, et al. (2011). Soy isoflavones in the prevention of menopausal bone loss and menopausal symptoms: a randomized, double-blind trial. Arch. Intern. Med. 171: 1363-1369.

Liang D, Yang M, Guo B, Cao J, et al. (2012). Zinc upregulates the expression of osteoprotegerin in mouse osteoblasts MC3T3-E1 through PKC/MAPK pathways. Biol. Trace Elem. Res. 146: 340-348.

Longo M, Peruzzi B, Fortunati D, De Luca V, et al. (2006). Modulation of human estrogen receptor alpha F promoter by a protein kinase C/c-Src-dependent mechanism in osteoblast-like cells. J. Mol. Endocrinol. 37: 489-502.

Mathey J, Mardon J, Fokialakis N, Puel C, et al. (2007). Modulation of soy isoflavones bioavailability and subsequent effects on bone health in ovariectomized rats: the case for equol. Osteoporos. Int. 18: 671-679.

Migliaccio S, Bernardini S, Wetsel WC, Korach KS, et al. (1998). Protein kinase C modulates estrogen receptors in differentiated osteoblastic cells in vitro. Steroids 63: 352-354.

Nakura A, Higuchi C, Yoshida K and Yoshikawa H (2011). PKCalpha suppresses osteoblastic differentiation. Bone 48: 476-484.

Occhiuto F, Pasquale RD, Guglielmo G, Palumbo DR, et al. (2007). Effects of phytoestrogenic isoflavones from red clover (Trifolium pratense L.) on experimental osteoporosis. Phytother. Res. 21: 130-134.

Ohtomo T, Uehara M, Penalvo JL, Adlercreutz H, et al. (2008). Comparative activities of daidzein metabolites, equol and O-desmethylangolensin, on bone mineral density and lipid metabolism in ovariectomized mice and in osteoclast cell cultures. Eur. J. Nutr. 47: 273-279.

Riggs BL, Khosla S and Melton LJ III (2002). Sex steroids and the construction and conservation of the adult skeleton. Endocr. Rev. 23: 279-302.

Setchell KD and Clerici C (2010). Equol: history, chemistry, and formation. J. Nutr. 140: 1355S-1362S.

Setchell KD, Brown NM, Desai PB, Zimmer-Nechimias L, et al. (2003). Bioavailability, disposition, and dose-response effects of soy isoflavones when consumed by healthy women at physiologically typical dietary intakes. $J$. Nutr. 133: 1027-1035.

Shedd-Wise KM, Alekel DL, Hofmann H, Hanson KB, et al. (2011). The soy isoflavones for reducing bone loss study: 3-yr effects on pQCT bone mineral density and strength measures in postmenopausal women. J. Clin. Densitom. 14: 47-57.

Shiguemoto GE, Rossi EA, Baldissera V, Gouveia CH, et al. (2007). Isoflavone-supplemented soy yoghurt associated with resistive physical exercise increase bone mineral density of ovariectomized rats. Maturitas 57: 261-270.

Taku K, Melby MK, Takebayashi J, Mizuno S, et al. (2010). Effect of soy isoflavone extract supplements on bone mineral density in menopausal women: meta-analysis of randomized controlled trials. Asia Pac. J. Clin. Nutr. 19: 33-42.

Taku K, Melby MK, Nishi N, Omori T, et al. (2011). Soy isoflavones for osteoporosis: an evidence-based approach. 
Maturitas 70: 333-338.

Tang CH, Yang RS, Huang TH, Liu SH, et al. (2004). Enhancement of fibronectin fibrillogenesis and bone formation by basic fibroblast growth factor via protein kinase C-dependent pathway in rat osteoblasts. Mol. Pharmacol. 66: 440-449.

Tang X, Zhu X, Liu S, Nicholson RC, et al. (2008). Phytoestrogens induce differential estrogen receptor beta-mediated responses in transfected MG-63 cells. Endocrine 34: 29-35.

Tyagi AM, Srivastava K, Mansoori MN, Trivedi R, et al. (2012). Estrogen deficiency induces the differentiation of IL-17 secreting Th17 cells: a new candidate in the pathogenesis of osteoporosis. PLoS One 7: e44552.

Villa I, Dal Fiume C, Maestroni A, Rubinacci A, et al. (2003). Human osteoblast-like cell proliferation induced by calcitonin-related peptides involves PKC activity. Am. J. Physiol. Endocrinol. Metab. 284: E627-E633.

Wong WW, Lewis RD, Steinberg FM, Murray MJ, et al. (2009). Soy isoflavone supplementation and bone mineral density in menopausal women: a 2-y multicenter clinical trial. Am. J. Clin. Nutr. 90: 1433-1439.

Yuan JP, Wang JH and Liu X (2007). Metabolism of dietary soy isoflavones to equol by human intestinal microflora implications for health. Mol. Nutr. Food Res. 51: 765-781.

Zavatti M, Resca E, Bertoni L, Maraldi T, et al. (2013). Ferutinin promotes proliferation and osteoblastic differentiation in human amniotic fluid and dental pulp stem cells. Life Sci. 92: 993-1003. 